\title{
Spectral and Structural Perspectives of 1,3,3-Trimethyl-2,6-diphenylpiperidin-4-one
}

\author{
K. Gokula Krishnan, C. Udhaya Kumar, T. Vidhyasagar, M. Velayutham Pillai, C. Ramalingan
}

\begin{abstract}
In this work, we report spectral, structural and computational studies on 1,3,3-trimethyl-2,6-diphenylpiperidin-4-one (TMP). The molecular structure of the title compound in the ground state has been investigated by DFT-B3LYP method with 6-311G $(d, p)$ basis set. The optimized structural parameters of the title compound acquired from DFT method has been found in accord with the single crystal XRD values. Vibrational and Mulliken analysis, frontier molecular orbitals and molecular electrostatic potential of the title compound have also been calculated and discussed. The small energy gap $\left(E_{\text {Hомо- }} E_{L U M O}\right)$ show that the charge transfer occurs within the molecule.
\end{abstract}

Keywords: 2,6-diphenylpiperidin-4-one, DFT, ${ }^{1} \mathrm{H}$ and ${ }^{13} \mathrm{C}$ NMR spectra, stereochemistry.

\section{INTRODUCTION}

Piperidine structural motif is found incorporated in a large number of alkaloids available naturally. Besides, it is also functionally important unit in medications and used as a building block in the synthesis of pharmaceuticals which are used as SSRIs (selective serotonin reuptake inhibitors) [1], neuroleptics (antipsychotics) [2], opioids [3] and anticancer compounds [4]. Similarly, piperidin-4-one derivatives are considered as a ubiquitous structural unit as it possesses both nucleophilic (NH) and electrophilic (-CO-) centres which could be modified and aid in building or expanding the structures conveniently. This is evidenced by the availability of literature reports [5-10] about the biologically active compounds of the piperidin-4-one.

There has been a constant interest for exploring the structure and reactivity of the molecules either existing or newly synthesized. In this regard, significant number of such

Revised Manuscript Received on December 05, 2019

* Correspondence Author

K. Gokula Krishnan ${ }^{\mathbf{a}, \mathbf{b}}$ a Department of Chemistry, School of Advanced Sciences, Kalasalingam Academy of Research and Education (Deemed to be University), Krishnankovil-626126, Tamil Nadu, India.

b Government Arts and Science College for Women, Karimangalam, Dharmapuri- 635 111, Tamil Nadu, India. Email: gokulakrishnank83@gmail.com

C. Udhaya Kumar, Department of Chemistry, School of Advanced Sciences, Kalasalingam Academy of Research and Education (Deemed to be University), Krishnankovil-626126, Tamil Nadu, India. Email: udkchemist@gmail.com

T. Vidhyasagar, Department of Chemistry, Annamalai University, Chidambaram-626126, Tamil Nadu, India. Email: tvschemau@gmail.com

M. Velayutham Pillai*, Department of Chemistry, School of Advanced Sciences, Kalasalingam Academy of Research and Education (Deemed to be University), Krishnankovil-626126, Tamil Nadu, India. Email: cmvpillai@gmail.com; m.velayuthampillai@klu.ac.in

C. Ramalingan**, Department of Chemistry, School of Advanced Sciences, Kalasalingam Academy of Research and Education (Deemed to be University), Krishnankovil-626126, Tamil Nadu, India. Email: ramalinganc@gmail.com studies revealing the properties experimentally as well as theoretically for piperidin-4-one analogues [11-14]. These studies explored the probable properties of interest related to biological applications [15-17], NLO properties and others [18-23]. Our research group is also interested in that and reported [24] the theoretical studies in addition to the experimental data obtained for a piperidin-4-one derivative.

In continuation of our works related to piperidin-4-one compounds, herein we report the combined structural investigation of 1,3,3-trimethyl-2,6-diphenylpiperidin-4-one (TMP), a six membered heterocyclic ring motif derived from 3-methylbutan-2-one, benzaldehyde and ammonium acetate by Mannich condensation and further methylation with methyl iodide. After crystallization, a single crystal of suitable size was analyzed to get the XRD data [25]. This experimental data was chosen as the basis and theoretical studies using DFT method has been carried out and the results were interpreted in this article.

\section{Methodology}

\section{A. General}

The solvents used for recrystallization was of analytical grade and used without further purification. Precoated silica gel on aluminum sheets (Type 60 GF254, Merck) were used for monitoring the reaction by thin layer chromatography. The Fourier Transform infra red spectrum was recorded on an AVATAR-330 FT-IR spectrometer (Thermo Nicolet) using $\mathrm{KBr}$ in pellet form. The ${ }^{1} \mathrm{H}$ and ${ }^{13} \mathrm{C}$ NMR spectra were recorded at operating frequencies of $400 \mathrm{MHz}$ and $100 \mathrm{MHz}$, in a Bruker ULTRASHIELD 400 PLUS instrument, using deuterated chloroform as the solvent. About $10 \mathrm{mg}$ and 50 $\mathrm{mg}$ of the compound (TMP) was taken respectively for recording ${ }^{1} \mathrm{H}$ NMR and ${ }^{13} \mathrm{C}$ NMR spectra. As an internal reference, tetramethylsilane (TMS) was used for both ${ }^{1} \mathrm{H}$ and ${ }^{13} \mathrm{C}$ NMR spectra, with chemical shifts reported in $\delta$ units (parts per million) relative to the standard. The signals in the ${ }^{1} \mathrm{H}$ NMR spectrum are designated as singlet (s), broad singlet (bs), doublet (d), doublet of doublet (dd), triplet (t) and multiplet $(\mathrm{m})$ and the coupling constants are expressed in Hertz (Hz).

\section{B. Synthesis of 1,3,3-trimethyl-2,6-diphenylpiperidin-4-one}

Good quality plagiarism software/ tool (Turnitin / The title compound (TMP) was synthesized [25] by following the procedure reported in the literature.

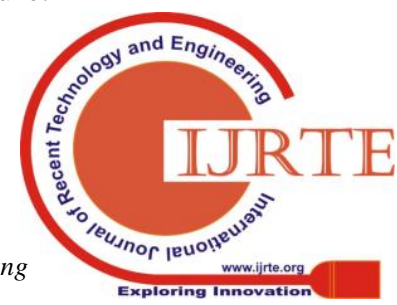




\section{Computational Details}

Theoretical calculation for the title compound (TMP) has been performed with the Gaussian 09W packages [26]. Geometry optimization of TMP in ground state has performed using hybrid functional B3LYP with a 6-311G $(d, p)$ basis set for all the atoms in gaseous state. The vibrational and Mulliken analysis, frontier molecular orbitals (FMOs) and molecular electrostatic potential (MEP) are calculated in order to understand the molecular interaction with another species around the space.

\section{A. Molecular Geometry}

\section{RESUltS AND DiscuSSION}

The molecular crystal of TMP has grown by slow evaporation technique using ethanol at room temperature. TMP has crystallized in the triclinic system with P-1 space group and four molecules are available per unit cell. An ORTEP view and the numbering scheme of TMP are shown in Figure 1. The structural features acquired by X-ray crystallographic analysis of the molecule TMP has been compared with the theoretically deduced one are tabulated in Table

1.

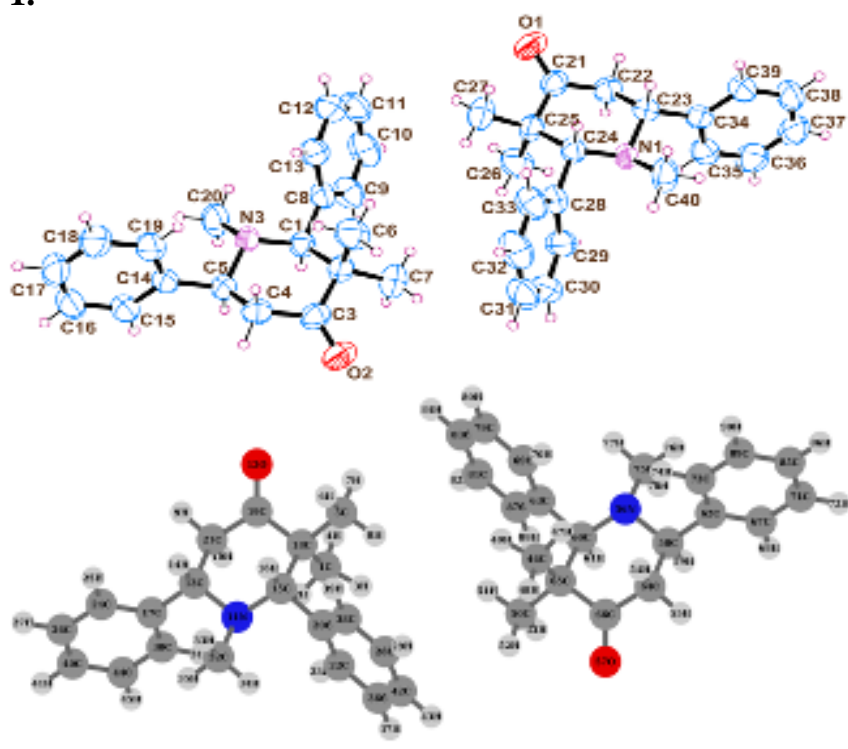

Figure 1 ORTEP view and numbering scheme of TMP

Table 1 Experimental and theoretical data pertaining to optimized molecular geometry of TMP

\begin{tabular}{|c|c|c|c|c|c|}
\hline Bond Length & Calc. & Expt. & Bond Length & Calc. & Expt. \\
\hline C1-C18 & 1.552 & $1.524(4)$ & C18-C19 & 1.529 & $1.515(4)$ \\
\hline C5-C18 & 1.539 & $1.529(4)$ & C19-C21 & 1.504 & $1.492(4)$ \\
\hline N11-C13 & 1.491 & $1.472(3)$ & C20-C22 & 1.405 & $1.380(4)$ \\
\hline $\mathrm{N} 11-\mathrm{C} 15$ & 1.497 & $1.478(3)$ & C20-C38 & 1.402 & $1.380(4)$ \\
\hline N11-C32 & 1.484 & $1.462(3)$ & C22-C36 & 1.396 & $1.379(4)$ \\
\hline O12-C19 & 1.242 & $1.209(3)$ & C24-C26 & 1.398 & $1.387(4)$ \\
\hline C13-C17 & 1.524 & $1.511(4)$ & C26-C40 & 1.396 & $1.356(4)$ \\
\hline C13-C21 & 1.548 & $1.524(4)$ & C28-C38 & 1.398 & $1.384(4)$ \\
\hline C15-C18 & 1.586 & $1.562(4)$ & C28-C42 & 1.397 & $1.356(5)$ \\
\hline $\mathrm{C} 15-\mathrm{C} 20$ & 1.525 & $1.513(4)$ & C30-C44 & 1.396 & $1.374(4)$ \\
\hline C17-C24 & 1.4 & $1.377(4)$ & C36-C42 & 1.399 & $1.362(4)$ \\
\hline C17-C30 & 1.404 & $1.385(4)$ & C40-C44 & 1.399 & $1.373(4)$ \\
\hline Bond Angle & Calc. & Expt. & Bond Angle & Calc. & Expt. \\
\hline C13-N11-C15 & 113.5 & $112.0(2)$ & O12-C19-C18 & 122.7 & $123.1(3)$ \\
\hline C13-N11-C32 & 109.6 & $108.2(2)$ & O12-C19-C21 & 121.7 & $121.4(3)$ \\
\hline C15-N11-C32 & 111.1 & $108.5(2)$ & C18-C19-C21 & 115.6 & $115.4(3)$ \\
\hline N11-C13-C17 & 112.2 & $110.7(2)$ & $\mathrm{C} 15-\mathrm{C} 20-\mathrm{C} 22$ & 121.7 & $121.6(3)$ \\
\hline N11-C13-C21 & 111.3 & $110.5(2)$ & C15-C20-C38 & 119.9 & $120.9(3)$ \\
\hline C17-C13-C21 & 109.2 & $109.7(2)$ & C22-C20-C38 & 118.4 & $117.5(3)$ \\
\hline N11-C15-C18 & 112.9 & $112.9(2)$ & C13-C21-C19 & 111.6 & $111.4(3)$ \\
\hline $\mathrm{N} 11-\mathrm{C} 15-\mathrm{C} 20$ & 111.2 & $109.8(2)$ & C20-C22-C36 & 120.7 & $121.2(3)$ \\
\hline $\mathrm{C} 18-\mathrm{C} 15-\mathrm{C} 20$ & 111.7 & $111.9(2)$ & C17-C24-C26 & 120.7 & $121.0(3)$ \\
\hline C13-C17-C24 & 120.4 & $120.7(3)$ & C24-C26-C40 & 120.1 & $120.4(3)$ \\
\hline C13-C17-C30 & 120.8 & $121.4(3)$ & C38-C28-C42 & 120.1 & $120.7(3)$ \\
\hline C24-C17-C30 & 118.8 & $117.9(3)$ & C17-C30-C44 & 120.6 & $120.6(3)$ \\
\hline C1-C18-C5 & 109.4 & $109.3(3)$ & C22-C36-C42 & 120.3 & $120.5(4)$ \\
\hline C1-C18-C15 & 112.6 & $112.9(3)$ & C20-C38-C28 & 121 & $120.8(3)$ \\
\hline C1-C18-C19 & 107.7 & $106.2(2)$ & C26-C40-C44 & 119.6 & $119.3(3)$ \\
\hline C5-C18-C15 & 110.2 & $109.4(2)$ & C28-C42-C36 & 119.5 & $119.4(4)$ \\
\hline C5-C18-C19 & 109.7 & $109.7(2)$ & C30-C44-C40 & 120.2 & $120.7(4)$ \\
\hline C15-C18-C19 & 107.2 & $109.3(2)$ & & & \\
\hline Dihedral Angle & Calc. & Expt. & Dihedral Angle & Calc. & Expt. \\
\hline C15-N11-C13-C17 & 176.1 & $-179.5(2)$ & C13-C17-C24-C26 & 176.9 & $179.4(3)$ \\
\hline C15-N11-C13-C21 & 53.5 & $58.8(3)$ & C30-C17-C24-C26 & -0.2 & $-0.4(5)$ \\
\hline C32-N11-C13-C17 & -59 & $-59.8(3)$ & C13-C17-C30-C44 & -177.1 & $-179.8(3)$ \\
\hline C32-N11-C13-C21 & 178.4 & $178.4(2)$ & C24-C17-C30-C44 & -0.1 & $0(5)$ \\
\hline C13-N11-C15-C18 & -55.7 & $-56.9(3)$ & C1-C18-C19-O12 & -111.7 & $-103.7(3)$ \\
\hline C13-N11-C15-C20 & 177.9 & $177.5(2)$ & C1-C18-C19-C21 & 68.7 & $74.6(3)$ \\
\hline C32-N11-C15-C18 & -179.8 & $-176.4(2)$ & C5-C18-C19-O12 & 7.4 & $14.3(4)$ \\
\hline C32-N11-C15-C20 & 53.8 & $58.0(3)$ & C5-C18-C19-C21 & -172.2 & $-167.4(3)$ \\
\hline N11-C13-C17-C24 & 133.9 & $125.2(3)$ & C15-C18-C19-O12 & 127 & $134.2(3)$ \\
\hline N11-C13-C17-C30 & -49.1 & $-55.0(4)$ & C15-C18-C19-C21 & -52.7 & $-47.5(3)$ \\
\hline
\end{tabular}




\begin{tabular}{|l|l|l|l|l|l|}
\hline C21-C13-C17-C24 & -102.2 & $-112.5(3)$ & O12-C19-C21-C13 & -126 & $-130.3(3)$ \\
\hline C21-C13-C17-C30 & 74.8 & $67.3(4)$ & C18-C19-C21-C13 & 53.6 & $51.4(4)$ \\
\hline N11-C13-C21-C19 & -51.2 & $-55.1(3)$ & C15-C20-C22-C36 & 178.9 & $-177.1(3)$ \\
\hline C17-C13-C21-C19 & -175.5 & $-177.5(2)$ & C38-C20-C22-C36 & -0.8 & $1.3(5)$ \\
\hline N11-C15-C18-C1 & -65.8 & $-68.7(3)$ & C15-C20-C38-C28 & -178.7 & $177.3(3)$ \\
\hline N11-C15-C18-C5 & 171.7 & $169.5(2)$ & C22-C20-C38-C28 & 0.9 & $-1.2(5)$ \\
\hline N11-C15-C18-C19 & 52.4 & $49.3(3)$ & C20-C22-C36-C42 & 0.1 & $-0.5(6)$ \\
\hline C20-C15-C18-C1 & 60.4 & $55.8(3)$ & C17-C24-C26-C40 & 0.2 & $0.6(5)$ \\
\hline C20-C15-C18-C5 & -62.1 & $-66.1(3)$ & C24-C26-C40-C44 & 0 & $-0.5(5)$ \\
\hline C20-C15-C18-C19 & 178.6 & $173.8(2)$ & C42-C28-C38-C20 & -0.4 & $0.3(6)$ \\
\hline N11-C15-C20-C22 & 46.2 & $43.5(4)$ & C38-C28-C42-C36 & -0.4 & $0.5(6)$ \\
\hline N11-C15-C20-C38 & -134.2 & $-135.0(3)$ & C17-C30-C44-C40 & 0.3 & $0.2(6)$ \\
\hline C18-C15-C20-C22 & -81 & $-82.7(3)$ & C22-C36-C42-C28 & 0.5 & $-0.4(6)$ \\
\hline C18-C15-C20-C38 & 98.6 & $98.9(3)$ & C26-C40-C44-C30 & -0.3 & $0.1(6)$ \\
\hline
\end{tabular}

The optimized structural parameters i.e. bond lengths, bond angles and dihedral angles of TMP have been determined using DFT-B3LYP method with 6-311G (d,p) basis set. The theoretical results revealed that the piperidine ring adopts a chair conformation which is indicated by the dihedral angles between the planes C13-C21 and C15-C18 as $-51.2[-55.1(3)]$ and $52.4[49.3(3)]$. Moreover, the two phenyl rings connected to the piperidine ring equatorially with the terminal bond angles of C13 and C15: 109.2 [109.7(2)] and 111.7 [111.9(2)], respectively. The optimized carbon-carbon $(\mathrm{C}-\mathrm{C}, \mathrm{C}=\mathrm{C})$ bond lengths in piperidine and phenyl rings are falling in the range (1.54 and $1.39 \AA$ ); which are closer to the experimental values for carbon-carbon bond (1.52 and 1.38 $\AA$ ). Theoretically investigated N11-C32

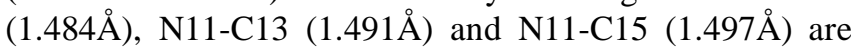
typical single bonds which agree well with the experimental ones. The bond length associated with carbonyl function $(\mathrm{C}=\mathrm{O} / 1.242 \AA)$ is closer to the experimental deduced $\mathrm{C}=\mathrm{O}$ bond length (1.209(3) $\AA$ ). The other bond lengths and angles computed by DFT calculations show good agreement with the corresponding single crystal XRD values.

Vibrational Analysis

The FT-IR spectrum of TMP has been recorded in the frequency range of 400-4000 $\mathrm{cm}^{-1}$ and shown in Figure 2. The strong and sharp absorption zone arises in the region of $1600-1750 \mathrm{~cm}^{-1}$ in the spectrum is assigned to carbonyl group present in the molecule [27]. The TMP showed strong absorption peak at $1713 \mathrm{~cm}^{-1}$ which reveals the presence of carbonyl group $(\mathrm{C}=\mathrm{O})$. Generally, the stretching frequencies of aromatic and aliphatic $\mathrm{C}-\mathrm{H}$ bands appeared in the region $2800-3100 \mathrm{~cm}^{-1}$ [27]. In the FT-IR spectrum, a collection of bands observed in the region $2776-3083 \mathrm{~cm}^{-1}$ are ascribed to the $\mathrm{C}-\mathrm{H}$ stretching frequencies of aromatic and aliphatic groups.

KALASALINGAM ACADEMY OF RESEARCH AND EDUCATION (DEEMED TO BE UNIVERSITY Sir C.V. RAMLN KRISHNAN

INTERNATIONAL. RESEARCH CENTRE

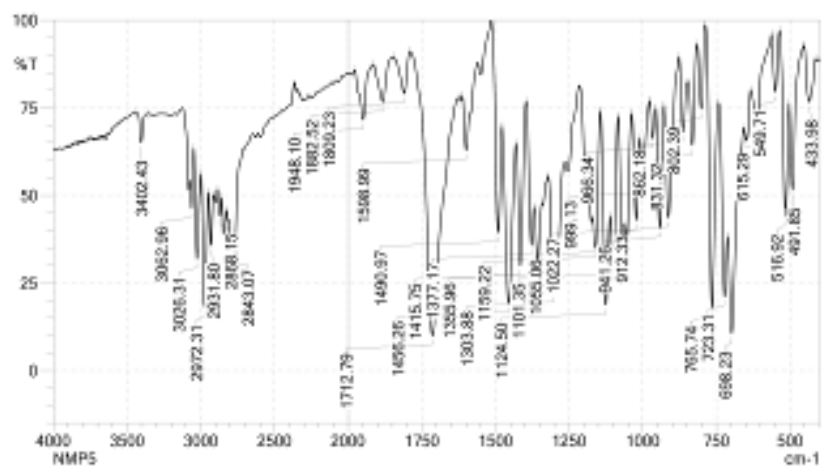

Figure 2 FT-IR spectrum of TMP

\section{B.Mulliken Population Analysis}

Mulliken population analysis is a noteworthy quantum chemical parameter to a molecular system due to the fact that the atomic charges influence dipole moment, molecular polarizability, electronic structure and many more properties of molecular systems [28]. Mulliken charge distribution of TMP has been acquired by B3LYP method with 6-311G (d,p) basis set and the data are given in Table 2 The results have been represented pictorially in Figure 3.

Table 2 Mulliken charge distribution of TMP

\begin{tabular}{|l|l|l|l|l|l|l|l|}
\hline Atom & $\begin{array}{l}\text { Charg } \\
\text { e }\end{array}$ & Atom & $\begin{array}{l}\text { Charg } \\
\text { e Atom }\end{array}$ & $\begin{array}{l}\text { Charg } \\
\mathbf{e}\end{array}$ & Atom & $\begin{array}{l}\text { Charg } \\
\text { e }\end{array}$ \\
\hline $\mathrm{C} 1$ & -0.5126 & $\mathrm{C} 24$ & -0.1234 & $\mathrm{C} 46$ & -0.5126 & $\mathrm{C} 69$ & -0.0882 \\
\hline $\mathrm{H} 2$ & 0.1943 & $\mathrm{H} 25$ & 0.1561 & $\mathrm{H} 47$ & 0.1943 & $\mathrm{H} 70$ & 0.1714 \\
\hline $\mathrm{H} 3$ & 0.2134 & $\mathrm{C} 26$ & -0.1620 & $\mathrm{H} 48$ & 0.1842 & $\mathrm{C} 71$ & -0.1620 \\
\hline $\mathrm{H} 4$ & 0.1842 & $\mathrm{H} 27$ & 0.1501 & $\mathrm{H} 49$ & 0.2134 & $\mathrm{H} 72$ & 0.1501 \\
\hline $\mathrm{C} 5$ & -0.4809 & $\mathrm{C} 28$ & -0.1611 & $\mathrm{C} 50$ & -0.4809 & $\mathrm{C} 73$ & -0.0837 \\
\hline
\end{tabular}




\section{Spectral and Structural Perspectives of 1,3,3-Trimethyl-2,6-diphenylpiperidin-4-one}

\begin{tabular}{|l|l|l|l|}
\hline $\mathrm{H} 6$ & 0.1707 & $\mathrm{H} 29$ & 0.1501 \\
\hline $\mathrm{H} 7$ & 0.1936 & $\mathrm{C} 30$ & -0.0837 \\
\hline $\mathrm{H} 8$ & 0.1983 & $\mathrm{H} 31$ & 0.1713 \\
\hline $\mathrm{H} 9$ & 0.2033 & $\mathrm{C} 32$ & -0.3868 \\
\hline $\mathrm{H} 10$ & 0.2214 & $\mathrm{H} 33$ & 0.1533 \\
\hline $\mathrm{N} 11$ & -0.4473 & $\mathrm{H} 34$ & 0.2112 \\
\hline $\mathrm{O} 12$ & -0.3477 & $\mathrm{H} 35$ & 0.2089 \\
\hline $\mathrm{C} 13$ & -0.1336 & $\mathrm{C} 36$ & -0.1596 \\
\hline $\mathrm{H} 14$ & 0.1635 & $\mathrm{H} 37$ & 0.1526 \\
\hline $\mathrm{C} 15$ & -0.0783 & $\mathrm{C} 38$ & -0.1344 \\
\hline $\mathrm{H} 16$ & 0.1621 & $\mathrm{H} 39$ & 0.1545 \\
\hline $\mathrm{C} 17$ & -0.0354 & $\mathrm{C} 40$ & -0.1292 \\
\hline $\mathrm{C} 18$ & -0.2157 & $\mathrm{H} 41$ & 0.1519 \\
\hline $\mathrm{C} 19$ & 0.3937 & $\mathrm{C} 42$ & -0.1290 \\
\hline $\mathrm{C} 20$ & -0.0400 & $\mathrm{H} 43$ & 0.1566 \\
\hline $\mathrm{C} 21$ & -0.4241 & $\mathrm{C} 44$ & -0.1633 \\
\hline $\mathrm{C} 22$ & -0.0881 & $\mathrm{H} 45$ & 0.1496 \\
\hline $\mathrm{H} 23$ & 0.1714 & & \\
\hline
\end{tabular}

Figure 3 Mulliken charge distribution of TMP

From the DFT-B3LYP calculation, it is observed that the atomic charges of TMP have covered a wide range of numerical values from -0.5126 to +0.3937 which suggests that the intramolecular charge transfer occur inside the molecule. The magnitude of the positive charge on carbon atoms C19 and C66 have been found to be a maximum of 0.3937 while all the other carbon atoms attained negative atomic charges. From this observation we know that, the carbon atoms (C19 and C66) which are directly attached to the electronegative atoms (O12 and $\mathrm{O} 57)$ results in electropositive character because of the attraction of the electrons from $\mathrm{C} 19$ and $\mathrm{C} 66$ by $\mathrm{O} 12$ and $\mathrm{O} 57$ and while the other carbon atoms behaves as electron acceptors. Further, all the hydrogen atoms present in the molecule acquired positive atomic charges.

\section{C.Frontier Molecular Orbitals (FMOs) Analysis}

\begin{tabular}{|l|l|l|l|}
\hline H51 & 0.1982 & H74 & 0.1713 \\
\hline H52 & 0.1936 & C75 & -0.3868 \\
\hline H53 & 0.1706 & H76 & 0.2089 \\
\hline H54 & 0.2214 & H77 & 0.2112 \\
\hline H55 & 0.2034 & H78 & 0.1533 \\
\hline N56 & -0.4472 & C79 & -0.1596 \\
\hline O57 & -0.3477 & H80 & 0.1526 \\
\hline C58 & -0.1336 & C81 & -0.1610 \\
\hline H59 & 0.1635 & H82 & 0.1501 \\
\hline C60 & -0.0784 & C83 & -0.1290 \\
\hline H61 & 0.1621 & H84 & 0.1565 \\
\hline C62 & -0.0354 & C85 & -0.1292 \\
\hline C63 & -0.0399 & H86 & 0.1519 \\
\hline C64 & -0.4241 & C87 & -0.1344 \\
\hline C65 & -0.2157 & H88 & 0.1545 \\
\hline C66 & 0.3937 & C89 & -0.1633 \\
\hline C67 & -0.1234 & H90 & 0.1496 \\
\hline H68 & 0.1561 & & \\
\hline & Th & & \\
\hline
\end{tabular}

The frontier molecular orbitals (FMOs) are important quantum chemical parameters to determine the optical and electric properties of a molecule. Generally, the highest occupied and lowest unoccupied MOs are represented as electron donor and acceptor, respectively. Besides, the energy gap between FMOs is generally investigated to determine the chemical stability, reactivity, hardness and softness of a molecule [29]. The 3D plot of FMOs of TMP can be visualized in Figure 4 and their corresponding energy gap values are presented in Table $\mathbf{3}$.

Table 3 FMO parameters of TMP

\begin{tabular}{|l|l|}
\hline $\begin{array}{c}\text { Parameter } \\
\mathbf{s}\end{array}$ & \multicolumn{1}{c|}{$\begin{array}{c}\text { Energies } \\
(\mathbf{e V})\end{array}$} \\
\hline HOMO & -8.2877 \\
\hline LUMO & -4.7610 \\
\hline$\Delta \mathrm{E}$ & 3.5267 \\
\hline
\end{tabular}

From the FMOs profile of TMP, the highest occupied MOs are nearly located over the nitrogen atom of the piperidine ring. On the other hand, the lowest unoccupied MOs are almost spread over two phenyl rings and carbonyl carbon of the piperidine ring. Thus, the electronic transition from the ground state to the excited state is clearly indicated by the flow of electron over the entire molecule. Further, the calculated HOMO, LUMO energies and energy gap between HOMO-LUMO of TMP are -8.2877 (HOMO), -4.7610 (LUMO) and $3.5267(\Delta \mathrm{E}) \mathrm{eV}$, respectively. 

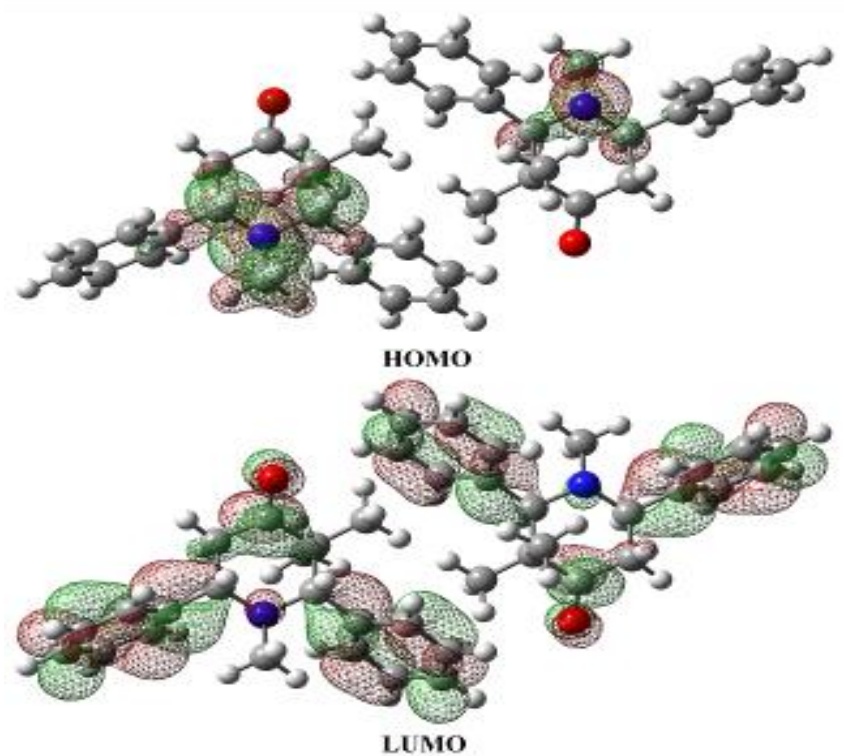

Figure 4 Frontier Molecular Orbitals (FMOs) picture of TMP

D. Molecular Electrostatic Potential (MEP) Analysis

A topographical MEP map has been extensively used to enlighten the features of chemical reactivity (electrophilic and nucleophilic sites), pharmacological activity and hydrogen bonding interactions of a molecule [30]. For knowing that, we have determined the molecular electrostatic potential and explained their spatial distribution over the molecule. The colour code of MEP map represents the electron rich zone as red in colour which is having partial negative charge; electron deficient regions represented by blue colour which holds partially positive charge; and neutral areas are designated as green in colour.

To predict the reactive sites of the analyzed molecule, the MEP has been calculated using optimized geometry at the B3LYP/6-311G (d,p) method in the gas phase. The MEP map of TMP, computed at 0.002 a.u isosurface is shown in Figure 5.

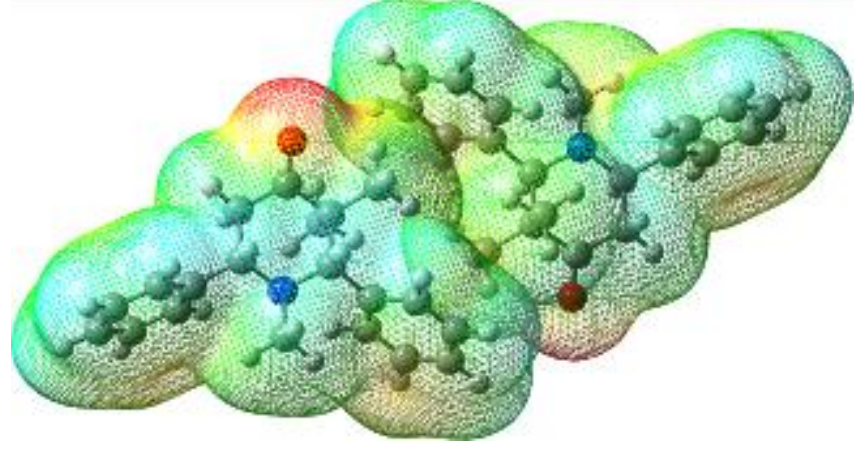

Figure 5 Molecular Electrostatic Potential (MEP) map of TMP

As can be seen in the figure, the negative potentials are mainly localized over the carbonyl oxygen while the positive regions spreaded over the nitrogen atom of the piperidine ring. These colour codes reflect that the region of electrophilic and nucleophilic reactivities and intermolecular interactions in the molecule. The calculated values of MEP global maxima and minima of the TMP are +58.73 and $-58.73 \mathrm{kcal} \mathrm{mol}^{-1}$. These values imply that the carbonyl region is favoring electrophilic attack. The predominance of the light-green region in the MEP surfaces corresponds to a potential halfway between the two extremes of red and blue colour.

\section{E. NMR analysis}

In the ${ }^{1} \mathrm{H}$ NMR spectrum of TMP (Figure 6), the three upfield signals corresponding to three protons each respectively at $0.85,1.28$ and $1.78 \mathrm{ppm}$ are assignable to the methyl group protons of C3-Me(eq), C3-Me(ax) and N-Me groups. The singlet at $3.14 \mathrm{ppm}$ with one proton integral is attributed to the $\mathrm{H} 2$ proton oriented axially in the piperidine ring. Of the two doublet of doublets found around 3.4 and 2.4 $\mathrm{ppm}$, the downfield signal at $3.35 \mathrm{ppm}$ is ascribable to the H6a proton and the upfield one is due to the resonance of $\mathrm{H} 5 \mathrm{e}$ proton. The triplet at $3.06 \mathrm{ppm}$ is due to the H5a proton. The resonances of aromatic protons are observed between 7.24 and $7.46 \mathrm{ppm}$ as a multiplet.

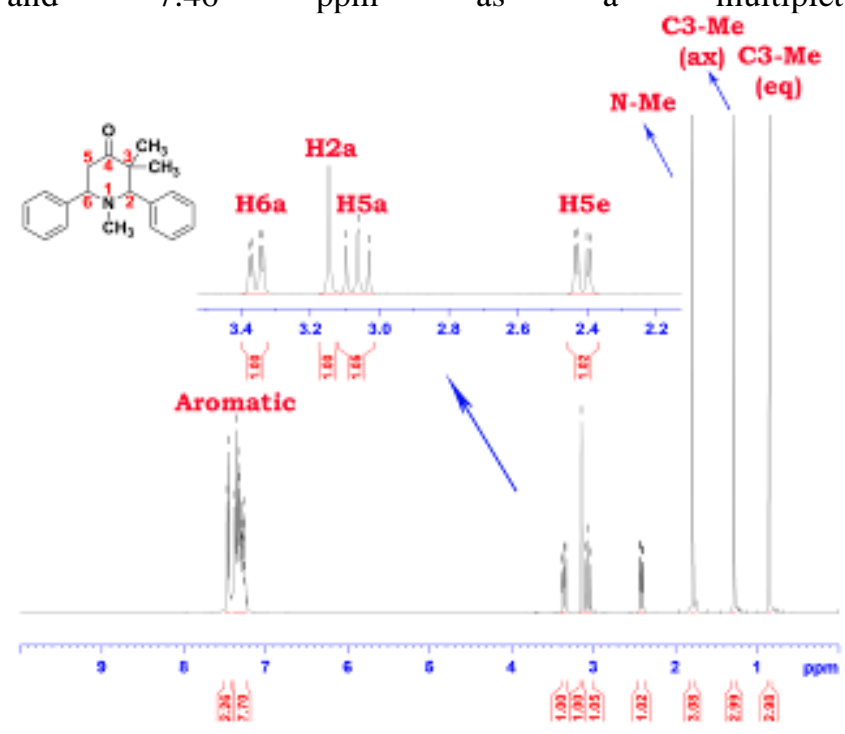

\section{Figure $6{ }^{1} \mathrm{H}$ NMR spectrum of TMP}

In the ${ }^{13} \mathrm{C}$ NMR spectrum of TMP (Figure 7), the axial and equatorial methyl carbons attached to the $\mathrm{C} 3$ carbon are found to resonate isochronously around $21 \mathrm{ppm}$. The N-Me carbon atom showed its signal at $42.4 \mathrm{ppm}$. The resonance of $\mathrm{C} 3$ and $\mathrm{C} 5$ carbons are observed with a difference of about 2 ppm respectively at 49.3 and $47.2 \mathrm{ppm}$. The $\mathrm{C} 2$ carbon experiences a downfield shift at $78.7 \mathrm{ppm}$ and the $\mathrm{C6}$ carbon experiences an upfield shift with respect to the former at $70.9 \mathrm{ppm}$. The far downfield signal at $212.1 \mathrm{ppm}$ is accountable due to the carbonyl carbon (C4). The unsymmetrical environment of the ipso carbons are exemplified by their varying chemical shifts at 138.7 and $143.9 \mathrm{ppm}$. Aromatic carbons of the phenyl rings collectively resonate between 127 and $129.8 \mathrm{ppm}$. 


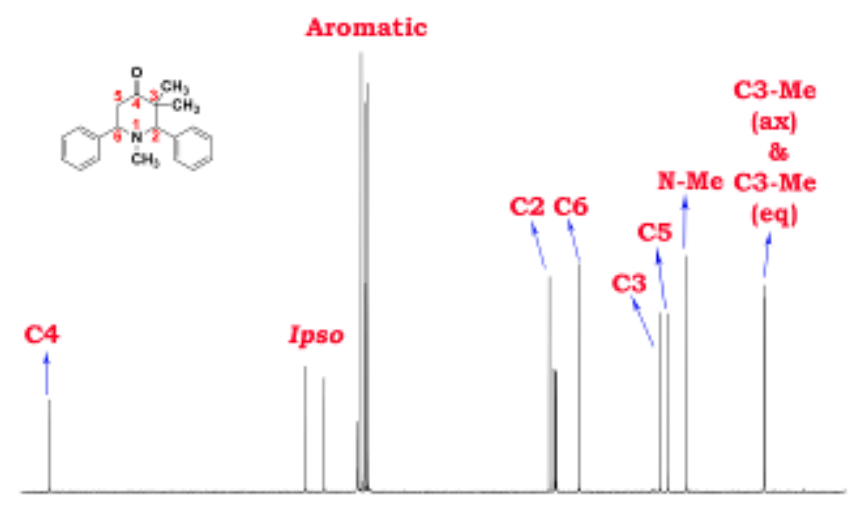

Figure $7{ }^{13} \mathrm{C}$ NMR spectrum of TMP

\section{F.Stereochemistry}

The magnitudes of vicinal coupling constants observed in a six membered cyclic system tell about the conformational preference of the ring. In the case of TMP, the diastereotopic methylene protons at C5 carbon namely H5a and H5e, couple unequally with the H6a proton and resulted in the formation of a triplet and two doublet of doublets. The magnitude of the coupling constant found in this AMX spin system of protons is greater than $10 \mathrm{~Hz}$ which is possible only when the dihedral angle between them is about $180^{\circ}$ allowing the substituents to take an equatorial orientation. The equatorial preference of the substituents present in the piperidine ring system facilitates the chair conformation which is favourable in the energy point of view. Hence, the piperidine ring system of TMP adopts a chair conformation with all the substituents in equatorial orientation and at C3 carbon, the second methyl group orients axially.

\section{Conclusion}

The effort to correlate the experimental and theoretical data to account for the structure and reactivity of the title molecules was achieved through DFT calculations. Optimized geometry, FMO visualization, vibrational and Mulliken population analyses, molecular electrostatic potential map, ${ }^{1} \mathrm{H}$ and ${ }^{13} \mathrm{C}$ NMR spectral interpretation have been carried out. Both the experimental and theoretical data supports a chair conformation for the piperidine ring system of TMP. The electron delocalization is ascertained by the HOMO-LUMO pictures. The electrophilic and nucleophilic nature of the constituent atoms of TMP is also accounted by Mulliken analysis. The spectral data is in accordance with the theoretical data computed.

\section{REFERENCES}

1. KumikoTakeuchi, Todd J. Kohn, Nicholas A. Honigschmidt, Vincent P. Rocco, Patrick G. Spinazze, Steven T. Atkinson, Larry W. Hertel, David L. Nelson, D. BradleyWainscott, Laura J. Ahmad, Janice Shaw, Penny G. Threlkeld, David T. Wong, "Advances toward new antidepressants beyond SSRIs: 1-aryloxy-3-piperidinylpropan-2-ols with dual 5-HT $1 \mathrm{~A}$ receptor antagonism/SSRI activities. Part 3", Bioorg. Med. Chem. Lett., Vol. 13 pp. 3939-3942, November 2003.

2. Jacek Wójcikowski,Patrick Maurel and Władysława A. Daniel, "Characterization of Human Cytochrome P450 Enzymes Involved in the
Metabolism of the Piperidine-type Phenothiazine Neuroleptic Thioridazine", Drug Metabolism and Disposition, Vol. 34 (3), pp 471-476, March 2006.

3. Bertrand Le Bourdonnec, Rolf T. Windh, Lara K. Leister, Q. Jean Zhou, Christopher W. Ajello, Minghua Gu, Guo-Hua Chu, Paul A. Tuthill, William M. Barker, Michael Koblish, Daniel D. Wiant, Thomas M. Graczyk, Serge Belanger, Joel A. Cassel, Marina S. Feschenko, Bernice L. Brogdon, Steven A. Smith, Michael J. Derelanko, Steve Kutz, Patrick J. Little, Robert N. DeHaven, Diane L. DeHaven-Hudkins and Roland E. Dolle, "Spirocyclic Delta Opioid Receptor Agonists for the Treatment of Pain: Discovery

$N, N$-Diethyl-3-hydroxy-4-(spiro[chromene-2,4'-piperidine]-4-yl)

Benzamide (ADL5747)", J. Med. Chem., Vol. 52(18), pp. 5685-5702, August 2009.

4. Pedro Martins, João Jesus, Sofia Santos, Luis R. Raposo, Catarina Roma-Rodrigues, Pedro Viana Baptista and Alexandra R. Fernandes, "Heterocyclic Anticancer Compounds: Recent Advances and the Paradigm Shift towards the Use of Nanomedicine's Tool Box", Molecules, Vol. 20(9), pp. 16852-16891, September 2015.

5. Sameer Rastogi, Harshita Rastogi, "An efficient synthesis of some substituted piperidin-4-one thiosemicarbazone derivatives as potential anticonvulsant under microwave irradiation", Indian J. Chem., Vol.49B, pp. 547-553, May 2010 .

6. Murugesan Srinivasan, Subbu Perumal and Sangavanaicker Selvaraj, "Synthesis, Stereochemistry and Antimicrobial Activity of 2,6-Diaryl-3(arylthio)piperidin-4-ones”, Chem. Pharm. Bull. Vol. 54(6), pp. 795-801, June 2006.

7. T. Maruthavanan and P. Venkatesan, "Synthesis of 4-hydroxy-3,4-dialkyl-2,6-diaryl-piperidine derivatives as potent antimicrobial agent", Nat. Prod. Res., Vol. 27(3), pp. 238-245, March 2013.

8. G.Sundararajan, D.Rajaraman, T.Srinivasan, D.Velmurugan, K.Krishnasamy, "Synthesis, characterization, computational calculation and biological studies of some 2,6-diaryl-1-(prop-2-yn-1-yl)piperidin-4-one oxime derivatives", Spectrochim. Acta A Mol. Biomol. Spectrosc., Vol. 139, pp. 108-118, March 2015.

9. Pattusamy Nithya, Fazlur-Rahman Nawaz Khan, Selvaraj Mohana Roopan, Uma Shankar, Jong Sung Jin, "Environmentally benign one-pot synthesis and antimicrobial activity of 1-methyl-2,6-diarylpiperidin-4-ones", Chemical Papers, Vol. 65 (5), pp. 743-746, July 2011.

10. Kodisundaram Paulrasu, Arul Duraikannu, Balasankar Thirunavukkarasu, 4-methyl-N'-(3-alkyl-2r,6c-diarylpiperidin-4-ylidene)-1,2,3-thiadiazole-5carbohydrazides with antioxidant, antitumor and antimicrobial activity", Org. Biomol. Chem., Vol. 12, pp.5911-5921, August 2014.

11. G. Velraj, S. Soundharam, C. Sridevi, "Structure, Vibrational, Electronic, NBO and NMR Analyses of 3-Methyl-2,6-diphenylpiperidin-4-one (MDPO) by Experimental and Teoretical Approach", J. Mol. Struct., Vol. 1060, pp. 156-165, February 2014.

12. A. Dhandapani, S. Manivarman, S. Subashchandrabose, H. Saleem, "Molecular structure and vibrational analysis on (E)-1-(3-methyl-2,6-diphenyl piperidin-4-ylidene) semicarbazide", J. Mol. Struct., Vol. 1058, pp. 41-50, January 2014.

13. T.Hemalatha, P.K.M.Imran, A.Gnanamani, S.Nagarajan, "Synthesis, antibacterial and antifungal activities of some $N$-nitroso-2,6-diarylpiperidin-4-one semicarbazones and QSAR analysis", Nitric Oxide, Vol. 19(4), pp. 303-311, December 2008.

14. A.Therasa Alphonsa, C. Loganathan, S. Athavan Alias AnandS.Kabilan, "FT-IR, FT-Raman, UV, NMR spectra and molecular structure investigation of (E)-2-(3-chloropyrazin-2-yl)-1-(3-ethyl-2, 6-diphenyl piperidin-4-ylidene) hydrazine: A combined experimental and theoretical study”, J. Mol. Struct., Vol. 1100, pp. 137-144, November 2015.

15. Nurcan Karaman, Yusuf Sicak, Tuğba Taşkın-Tok, Mehmet Öztürk, Ayşegül Karaküçük-İyidoğan, Miris Dikmen, Bedia Koçyiğit-Kaymakçıŏlu, Emine Elçin Oruç-Emre, "New piperidine-hydrazone derivatives: Synthesis, biological evaluations and molecular docking studies as AChE and BChE inhibitors", Eur. J. Med. Chem., Vol. 124, pp. 270-283, November 2016.

16. Suvankar Das, Cristiane J. da Silva, Marina de M. Silva, Maria Dayanne de A. Dantas, Ângelo de Fátima, Ana Lúcia T. Góis Ruiz, Cleiton M. da Silva, João Ernesto de Carvalho, Josué C.C. Santos, Isis M. Figueiredo, Edeildo F. da SilvaJúnior, Thiago M. de Aquino, João X. de Araújo-Júnior, Goutam Brahmachari, Luzia Valentina Modolo, "Highly functionalized piperidines: Free radical scavenging, anticancer activity, DNA interaction and correlation with biological activity", Journal of Advanced Research, Vol. 9, pp. 51-61, January 2018. 
17. Shaimaa A. Abdelatef1, Mohammed T. El-Saadi, Noha H. Amin, Ahmed H. Abdelazeem, Khaled R.A. Abdellatif, "Synthesis and Anticancer Screening of Novel Spiro[Chroman-2,4'- Piperidin]-4-one Derivatives with Apoptosis-Inducing Activity", Journal of Applied Pharmaceutical Science, Vol. 8(01), pp 009-016, January 2018.

18. T. Suresh, S. Sarveswari, N. Arul Murugan, V. Vijayakumar, P. Iniyavan, A. Srikanth, Jerry P.Jasinski, "Synthesis, Spectral Characterization and DFT Analysis for the Validation of 2,6-diarylpiperidin-4-ones as Potential Sunscreens and UV Filters", J. Mol. Struct., Vol. 1099, pp. 560-566, November 2015

19. A. Thirunavukkarasu, R. Karunathan, J. Mallika, V. Sathyanarayanamoorthi, "Vibrational and quantum chemical analysis of 3-methyl-2,6-diphenyl piperidin-4-one using HF and DFT methods", Indian J. Pure Ap. Phy., Vol 52(10), pp. 653-670, October 2014.

20. D. Sridher, V. Sathya Narayana Moorthi, J. Mallika and V. Kannappan, “A Comprehensive Account of Spectral, NLO,NBO Analysis, Hartreefock and Density Functional Theory Studies of 1-Methyl 2, 6-Diphenyl Piperidin-4-one", Orient J Chem., Vol. 32(4), pp. 1883-1893, August 2016

21. V. Mohanraj, P. Sakthivel, S. Ponnuswamy, P. Muthuraja, M. Dhandapani, "Growth, spectral, thermal, NLO studies and computational studies on novel NLO organic crystals of $N$-Nitroso- $r$-2,c-6-bis(4-methoxyphenyl)-t-3-ethyl-piperidin-4-one", Materials Today: Proceedings, Vol. 8(1), pp. 1-10, April 2019,

22. R. Arulraj, S.Sivakumar, K.Rajkumar, Jerry P.Jasinski, Manpreet Kaur, A Thiruvalluvar, "Synthesis, Crystal Structure, DFT Calculations and Hirshfeld Surface Analysis of 3-Chloro-3-methyl-r(2),c(6)-bis( $p$-methoxyphenyl)piperidin-4-one", J. Chem. Crystallogr., Vol. , pp. 1-10, January 2019.

23. Poyyamozhi Surendar Anand, Annamalai Sethukumar, Chandran Udhaya Kumar, Kuppusamy Krishnasamy, Sivakolunthu Senthan, Govindhasamy Manikandan,' Balasubramaniam ArulPrakasam, 'Synthesis, spectroscopic investigation, computational, stereochemical and biological studies of 1,3-dimethyl-2,6-diphenylpiperidin-4-one

$N\left(4^{\prime}\right)$-cyclohexylsemicarbazone: Crystal structure and Hirshfeld surface analysis", Chemical Data Collections, Vol. 21, pp. 100216, June 2019.

24. M. Velayutham Pillai, K Rajeswari, T Vidhyasagar, "Spectral assignments and structural studies of a warfarin derivative stereoselectively formed by tandem cyclization", J. Mol. Struct., Vol. 1100, pp. 447-454, November 2015 .

25. T. Mohandas, M. Velayutham Pillai, A. Ragu, T. Vidhyasagar and P. Sakthivel, "Structural and conformational studies of 1,3,3-trimethyl-2,6diphenylpiperidin-4-one", Der Chemica Sinica, Vol. 5(5), pp. 46-49, 2014

26. Gaussian 09, Revision A.02, M. J. Frisch, G. W. Trucks, H. B. Schlegel, G. E. Scuseria, M. A. Robb, J. R. Cheeseman, G. Scalmani, V. Barone, G. A Petersson, H. Nakatsuji, X. Li, M. Caricato, A. Marenich, J. Bloino, B. G. Janesko, R. Gomperts, B. Mennucci, H. P. Hratchian, J. V. Ortiz, A. F. Izmaylov, J. L. Sonnenberg, D. Williams-Young, F. Ding, F. Lipparini, F. Egidi, J. Goings, B. Peng, A. Petrone, T. Henderson, D. Ranasinghe, V. G. Zakrzewski, J. Gao, N. Rega, G. Zheng, W. Liang, M. Hada, M. Ehara, K. Toyota, R. Fukuda, J. Hasegawa, M. Ishida, T. Nakajima, Y. Honda, O. Kitao, H. Nakai, T. Vreven, K. Throssell, J. A. Montgomery, Jr., J. E. Peralta, F. Ogliaro, M. Bearpark, J. J. Heyd, E. Brothers, K. N. Kudin, V. N. Staroverov, T. Keith, R. Kobayashi, J. Normand, K. Raghavachari, A. Rendell, J. C. Burant, S. S. Iyengar, J. Tomasi, M. Cossi, J. M. Millam, M. Klene, C. Adamo, R. Cammi, J. W. Ochterski, R. L. Martin, K. Morokuma, O. Farkas, J. B. Foresman, and D. J. Fox, Gaussian, Inc., Wallingford CT, 2016.

27. G. Socrates, "Infrared and Raman Characteristic group Frequencies, Tables and Charts", $3^{\text {rd }}$ Ed., Wiley, Chichester, 2001

28. R. Santamaria, G. Cocho, L. Corona, E. Gonzalez, "Molecular electrostatic potentials and Mulliken charge populations of DNA mini-sequences", Chem. Phy., Vol. 227, pp. 317-329, 1998.

29. A. Rauk, "Orbital Interaction Theory of Organic Chemistry", $2^{\text {nd }}$ Ed., Wiley Inter Science, New York, 2001

30. P. Politzer, P. R. Laurence, K. Jayasuriya, "Molecular Electrostatic Potentials: An Effective Tool for the Elucidation of Biochemical Phenomena”, Environ. Health Perspect. Vol. 61, pp. 191-202, 1985.

\section{AUTHORS PROFILE}

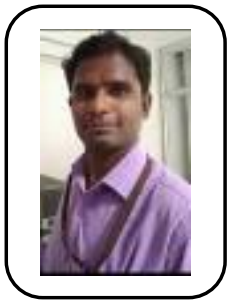

Dr. K. Gokula Krishnan Graduated from Sacred Heart College, Thiruppathur (2009) and pursued doctoral research in Organic Chemistry at Annamalai University (2011-‘15). He has published 10 research articles in peer-reviewed, indexed journals with good impact factor (Total citations: $36, h$-index: 3 ). His area of research are Organic Synthesis, Spectral Studies, Biological Studies and Computational Chemistry. During his post-doctoral research (2016-'19) at Kalasalingam University, Krishnankovil, he designed and synthesized compounds which found useful for anti-cancer applications. He is a Life Member of Association of Environmental Analytical Chemistry of India (AEACI) and Indian Science Congress Association (ISCA).

Dr. C. Udhaya Kumar Graduated from Thyagaraja College, Madurai (2009) and pursued doctoral research in Organic Chemistry at Annamalai University (2010-'14). He has published 24 research articles in peer-reviewed, indexed journals with good impact factor (Total citations: 57, $h$-index: 4 , ilo-index: 2 ). His area of research are Organic Synthesis, Spectral Studies, Single Crystal X-ray diffraction Studies and Computational Chemistry. During his post-doctoral research (2015-'18) at Kalasalingam University, Krishnankovil, he designed and synthesized compounds which found useful for fabricating Dye Sensitized Solar Cells (DSSCs). He is a Life Member of Association of Environmental Analytical Chemistry of India (AEACI).

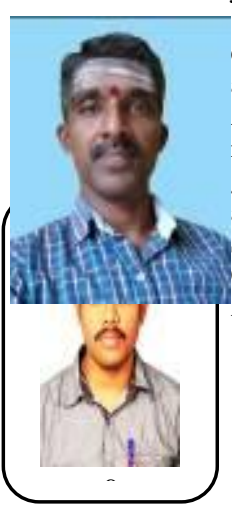

Dr. M. Velayutham Pillai had his under graduate education from Christian College, Nagercoil (1995-'97) and pursued doctoral research in Organic Chemistry at Annamalai University (2010-'14). He has published 14 research articles in peer-reviewed, indexed journals with good impact factor (Total citations: $17, h$-index: 2 ). His area of research are Organic Synthesis, Spectral Studies, Single Crystal X-ray diffraction Studies and Computational Chemistry. Presently he is working as Assistant Professor of Chemistry at Kalasalingam University, Krishnankovil (Tamil Nadu). He is a Life Member of Association of Environmental Analytica Chemistry of India (AEACI), Indian Science Congress Association (ISCA), Association of Separation Scientists and Technologists (ASSET), Indian Chromatographic Society of India (CSI).

Association

(ICA)

and

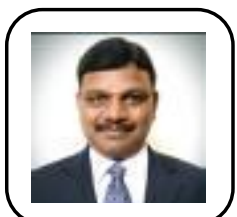

Dr. Chennan Ramalingan is serving as Professor of Chemistry at KARE. He received $\mathrm{PhD}$ in Organic Chemistry from Annamalai University in 2002. After he served as Research Professor at Kyungpook National University, South Korea followed by Assistant Professor at Osaka University, Japan, he joined at Kalasalingam Academy of Research and Education, Krishnankoil in late 2011. His research interests include organic synthesis, medicinal chemistry and material chemistry. He published more than 70 International research articles.

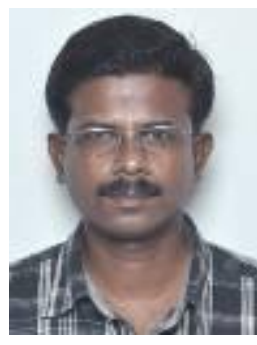

Dr. T. Vidhyasagar graduated from Annamalai University, Chidambaram (1997) and pursued doctoral research in Physical Organic Chemistry from the same during the year 2002. He has been working as a Faculty Member - Department of Chemistry, Annamalai University since 2003. To his credit, he has published 21 research articles in peer-reviewed and indexed journals of repute (Citations: $15, h$-index: 2 ). He has been teaching Inorganic Chemistry to UG and PG students of Chemistry for 16 years and supervised 3 doctoral research scholars. He is a Life Member of Association of Chemistry Teachers (ACT) and Chemical Research Society of India (CRSI). 